\title{
PREFACE
}

The Italian territory is vulnerable and is often affected by important natural phenomena. These are not always predictable, and we must learn to defend ourselves from them.

In these days of 2012, the seismic events in northern Italy have severely stretched the social and industrial structure of one of the most productive areas of Europe, the richness of which derives from a special combination of natural, cultural, social and economic factors, which need to be carefully preserved and valued.

Even the scientific community of the Earth sciences is called upon to take on this difficult task. Careful reflection of the ethical value and social impact of our studies can no longer be postponed, if we, as geoscientists, want to have an active role in society.

The population wishes for answers that are scientifically valid, and asks for rational support, instead of the instinctual irrationality that characterizes the fear of natural disasters. They also demand reliable solutions for managing our land and natural resources, from a sustainability perspective.

It is duty of the scientific community to provide the appropriate technical and cultural tools through information and education campaigns, so that society can become more aware and more prepared to participate in the debate on the best strategies to be adopted for the planning of our future development, while respecting the cultural and natural vocation of the territories.

This commitment and this responsibility of the scholars of the Earth sciences provides the term 'geoethics'.

This special volume of the Annals of Geophysics, the journal of the Istituto Nazionale di Geofisica e Vulcanologia (National Institute of Geophysics and Volcanology), represents a turning point in this regard. Thanks to the efforts of the two Editors, Silvia Peppoloni and Giuseppe Di Capua, the themes of geoethics can finally find the space and attention they deserve in a special issue entirely devoted to them by a JCR journal.

This volume will help to raise new questions and will provide new points for reflection. We believe that it will be helpful to foster the cultural change that is necessary to give a new perspective to the Earth sciences, as a group of disciplines that are serving the common good.

\section{Stefano Gresta,}

President, Istituto Nazionale di Geofisica e Vulcanologia 